\title{
A pandemia no cárcere: intervenções no superisolamento
}

Sérgio Garófalo de Carvalho (https://orcid.org/0000-0001-5936-9601) ${ }^{1}$ Andreia Beatriz Silva dos Santos (https://orcid.org/0000-0003-3755-021X) ${ }^{2}$ Ivete Maria Santos (https://orcid.org/0000-0001-8630-0503) ${ }^{1}$
${ }^{1}$ Universidade Federal da Bahia. R. Augusto Viana s/n, Palácio da Reitoria. 40110-909 Canela Salvador BA Brasil.sergiogarofalo@ hotmail.com

${ }^{2}$ Secretaria de

Administração Penitenciária

e Ressocialização. Salvador

BA Brasil.
Resumo Saúde prisional é, em sua essência, saúde pública. A pandemia de COVID-19 representa uma grande ameaça para o mundo e tem demonstrado que prevenir a escalada da doença em prisões faz parte do combate ao novo coronavírus na sociedade em geral. Sabe-se, até o momento, que a mais efetiva medida de contenção ao avanço da doença é o isolamento social. No entanto, em instituições penais, muitas vezes superlotadas, tal medida torna-se de difícil implementação e, quando acontece, leva a população privada de liberdade a um superisolamento, tendo consequências em sua saúde mental. Além disso, indivíduos presos sofrem com ambientes sem ventilação, falta de materiais de higiene pessoal, condições sanitárias básicas precárias e dificuldade de acesso a serviços de saúde. $O$ presente artigo objetiva ser uma revisão narrativa sobre os efeitos da pandemia em presídios e como governos e sociedade civil têm se organizado a fim de reduzir as consequências sobre esses locais. A publicação foi dividida em três seções: na primeira, há uma revisão da literatura em saúde sobre a temática; na segunda, é tratado o modo como diferentes países estão lidando com a situação carcerária no contexto da pandemia; na terceira e última parte, é abordado o modo como o Sistema Penal brasileiro tem reagido à nova doença.

Palavras-chave Prisões, Prisioneiros, SARSCoV-2, Pandemia por COVID-19 


\section{Introdução}

O surto da doença (COVID-19) causada pelo novo coronavírus (SARS-CoV-2) na China ganhou destaque global e foi declarada pandemia pela Organização Mundial da Saúde (OMS) em 11 de março de 2020. Como não existem tratamentos e vacinas específicas disponíveis para o controle da doença, a pandemia de COVID-19 representa uma grande ameaça para a saúde pública no mundo, exigindo ações de prevenção, tais como isolamento social e reforço de medidas de higiene ${ }^{1}$.

Já é sabido o potencial de transmissão do vírus quando em ambientes fechados e com aglomerações. Mizumoto e Chowell ${ }^{2}$ descreveram a evolução epidemiológica dentro de um cruzeiro asiático, em que o número médio de reprodução no ambiente confinado atingiu valores próximos a 11, o que é mais alto do que as estimativas relatadas na dinâmica de transmissão comunitária na China e na Cingapura, que vão de 1,1 a 7 . Neste navio, os casos passaram de 1 para $454 \mathrm{em}$ apenas 16 dias. A gripe espanhola afetou cerca de um quarto de todos presos, uma prevalência muito maior em comparação com os dados da população em geral ${ }^{3}$.

Instituições penais conferem um confinamento imposto por uma autoridade judicial e são cercadas por estigma e vulnerabilidade ${ }^{4}$. O confinamento dentro de uma unidade prisional é distinto de outros tipos, como cruzeiros, escolas, quarentena, que são isolamentos voluntários, ao passo que na prisão a liberdade está cerceada involuntariamente. Nesse sentido, quando aplicada ao contexto prisional, a medida de isolamento resulta em uma superposição de confinamentos, a qual intitulamos de superisolamento.

Muitos presídios no Brasil e no mundo são superlotados, oferecendo pouco espaço em relação ao preconizado para adequado distanciamento. Dos países, $59 \%$ possuem taxas de ocupação prisional que excedem a capacidade relatada ${ }^{5}$. Com isso, é alta a possibilidade de que o coronavírus seja rapidamente transmitido no interior das instituições penais. Em um só dia em fevereiro, a China registrou 200 contaminados em uma de suas prisões, isso quando a curva de infecções já estava em queda no país ${ }^{6}$.

Além de se tratar de um grande risco para as pessoas privadas de liberdade, uma alta prevalência de infecções respiratórias virais em populações prisionais pode servir como fonte potencial de infecção para a população em geral. Isso porque os presídios são instituições porosas, tais como as fronteiras dos países no mundo globa$\mathrm{lizado}^{7}$. Por meio de agentes penitenciários, trabalhadores, visitantes, presos libertados e transferidos, o coronavírus pode transitar por entre as grades do sistema prisional e ser transmitido às comunidades locais 8 .

Por definição, saúde prisional é saúde pública e deve ser tratada como tal por governantes e pela comunidade científica. Desse modo, o presente artigo se trata de uma revisão narrativa sobre o SARS-CoV-2 e a população carcerária, a fim de reunir o que se tem publicado sobre o assunto em revistas da área de saúde e elucidar o tema, com o objetivo de reforçar a necessidade de garantir direitos humanos fundamentais às pessoas privadas de liberdade e salvaguardar a saúde da população geral.

Para melhor leitura e compreensão do assunto, esta publicação está dividida nos seguintes tópicos: o estado da arte sobre COVID-19 e população carcerária; medidas de prevenção à COVID-19 em presídios no mundo; o enfrentamento ao novo coronavírus no sistema penitenciário brasileiro e considerações finais.

\section{O estado da arte sobre COVID-19 e população carcerária}

Para a realização desta revisão narrativa, foram pesquisados artigos publicados até 25 de abril de 2020 em revistas da área de saúde. Foram incluídos textos em inglês, espanhol e português e em quaisquer formatos, tais como editoriais, comentários, correspondências, opiniões, estudos empíricos e outros.

A busca ocorreu em duas bases de dados, PubMed e Google Scholar, a estratégia de pesquisa se encontra no Quadro 1. Foram encontrados 605 resultados e, após leitura do título e/ou resumo, restaram para leitura completa 13 artigos. Não foi realizada avaliação formal da qualidade, mas foram consideradas as importantes características metodológicas ao interpretar os resultados aqui apresentados narrativamente.

No PubMed, foram encontrados 3.710 artigos na busca pelo descritor "COVID-19", mas apenas seis publicações $(0,16 \%)$ tratando da pandemia no contexto carcerário. Dos 13 artigos incluídos nesta revisão, apenas um se trata de um estudo original. No Quadro 2, pode-se ver a descrição desses trabalhos.

O distanciamento social é praticamente impossível em instalações correcionais, onde os indivíduos vivem em confinamento em ambientes superlotados e com pouca ventilação, compar- 
Quadro 1. Estratégia de pesquisa em bases de dados.

\begin{tabular}{|c|c|}
\hline PubMed & Google Scholar \\
\hline 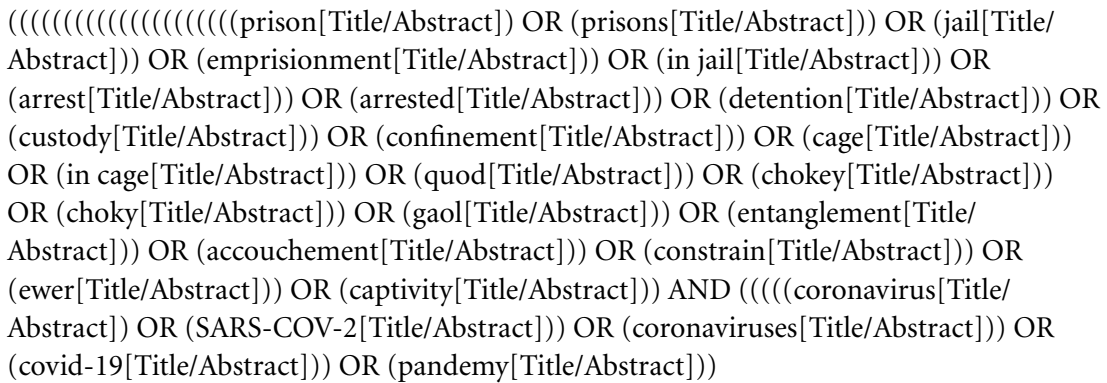 & $\begin{array}{l}\text { - COVID-19 AND } \\
\text { prisons }\end{array}$ \\
\hline
\end{tabular}

Quadro 2. Publicações incluídas na revisão.

\begin{tabular}{|c|c|c|c|}
\hline Título & Autores & $\begin{array}{c}\text { Tipo de } \\
\text { publicação }\end{array}$ & Revista \\
\hline $\begin{array}{l}\text { Covid-19, prison crowding, and release } \\
\text { policies }\end{array}$ & Simpson e Butler ${ }^{9}$ & Editorial & BMJ \\
\hline $\begin{array}{l}\text { COVID-19 and the coming epidemic in US } \\
\text { immigration detention centres }\end{array}$ & Meyer et al. ${ }^{10}$ & Comentário & Lancet Infect Dis \\
\hline Fighting covid-19 outbreaks in prisons & Yang e Thompson $^{11}$ & Correspondência & BMJ \\
\hline $\begin{array}{l}\text { Flattening the Curve for Incarcerated } \\
\text { Populations - Covid-19 in Jails and Prisons }\end{array}$ & Akiyama et al. ${ }^{7}$ & Perspectiva & N Engl J Med. \\
\hline $\begin{array}{l}\text { Prisons and custodial settings are part of a } \\
\text { comprehensive response to COVID-19 }\end{array}$ & Kinner et al. ${ }^{12}$ & Comentário & Lancet Public Health \\
\hline $\begin{array}{l}\text { COVID-19 and Immigration Detention in } \\
\text { the USA: Time to Act }\end{array}$ & Keller e Wagner ${ }^{13}$ & Comentário & Lancet Public Health \\
\hline $\begin{array}{l}\text { Spotlight on Jails: COVID-19 Mitigation } \\
\text { Policies Needed Now }\end{array}$ & Wurcel et al. ${ }^{14}$ & Correspondência & Clin Infect Dis. \\
\hline $\begin{array}{l}\text { COVID-19 Pandemic Poses Challenge for } \\
\text { Jails and Prisons }\end{array}$ & Stephenson $^{15}$ & Comentário & JAMA Health Forum \\
\hline $\begin{array}{l}\text { Detained during a pandemic: A postcard } \\
\text { from the Midwest }\end{array}$ & $\begin{array}{l}\text { Gorman e } \\
\text { Ramaswamy }^{16} \\
\end{array}$ & Editorial & Public Health Nurs. \\
\hline $\begin{array}{l}\text { The challenge of preventing COVID-19 } \\
\text { spread in correctional facilities }\end{array}$ & $\operatorname{Rubin}^{17}$ & Perspectiva & JAMA \\
\hline $\begin{array}{l}\text { Preparedness, prevention and control of } \\
\text { COVID-19 in prisons and other places of } \\
\text { detention }\end{array}$ & $\begin{array}{l}\text { World Health } \\
\text { Organization }^{18}\end{array}$ & $\begin{array}{l}\text { Documento } \\
\text { técnico }\end{array}$ & $\begin{array}{l}\text { World Health } \\
\text { Organization }\end{array}$ \\
\hline $\begin{array}{l}\text { Caring for persons in detention suffering } \\
\text { with mental illness during the Covid-19 } \\
\text { outbreak }\end{array}$ & Liebrenz et al. ${ }^{19}$ & Comentário & $\begin{array}{l}\text { Forensic science } \\
\text { international. Mind } \\
\text { and law }\end{array}$ \\
\hline $\begin{array}{l}\text { The Epidemiological Implications of } \\
\text { Incarceration Dynamics in Jails for } \\
\text { Community, Corrections Officer, and } \\
\text { Incarcerated Population Risks from } \\
\text { COVID-19 }\end{array}$ & Lofgren et al. ${ }^{20}$ & $\begin{array}{l}\text { Preprint: } \\
\text { Modelagem } \\
\text { matemática }\end{array}$ & medRxiv \\
\hline
\end{tabular}

tilham banheiros e chuveiros, além de áreas comuns como refeitórios, pátios e salas de aula ${ }^{10}$. A higienização das mãos é prejudicada por políticas que limitam o acesso ao sabão, além de muitas prisões restringirem a entrada de álcool, temendo que as pessoas o ingiram ${ }^{14}$.

As populações privadas de liberdade têm uma prevalência aumentada de doenças infec- 
ciosas, como infecções por HIV e vírus da hepatite $\mathrm{C}(\mathrm{HCV})^{7}$. As iniquidades nos determinantes sociais da saúde que afetam grupos que são desproporcionalmente passíveis de encarceramento - minorias raciais e sexuais, pessoas com transtornos mentais ou por uso de substâncias psicoativas, indivíduos sem acesso ao sistema de saúde ou à educação - levam a maiores concentrações de algumas doenças em populações encarceradas $^{7}$. O risco para uma pessoa privada de liberdade desenvolver tuberculose no Brasil é 30 vezes maior do que a população geral brasileira ${ }^{21}$. As doenças infecciosas são responsáveis por cerca de $17,5 \%$ das mortes nas prisões ${ }^{11}$.

Além das dificuldades relacionadas às estruturas física e social, já citadas, existem desafios administrativos - em grande parte causados pela falta ou má gestão de recursos financeiros ${ }^{14}$, o que pode dificultar o acesso de possíveis presos com COVID-19 à adequada atenção à saúde em caso de necessidade de suporte avançado. Os direitos de todas as pessoas afetadas devem ser respeitados e todas as medidas de saúde pública devem ser executadas sem discriminação de qualquer tipo ${ }^{18}$.

Todas as publicações revisadas salientam a premência de se tomarem medidas de prevenção ao SARS-CoV-2 em ambientes prisionais, é necessário considerar as cadeias como reservatórios que podem levar ao ressurgimento da epidemia, se esta não for tratada adequadamente nessas instalações ${ }^{7}$. Para tanto, três premissas devem ser cumpridas: a entrada do vírus em penitenciárias deve ser adiada tanto quanto possível; se já estiver em circulação, deve ser controlado e, por fim, as prisões devem se preparar para lidar com os que desenvolverem COVID-197.

Dada a dinâmica epidemiológica da $\mathrm{CO}$ VID-19, na ausência de qualquer intervenção, entre os encarcerados, o surto é consideravelmente mais grave do que na população geral, exigindo mais hospitalização e levando a mais óbitos. O pico da epidemia dentro de uma instituição penal, segundo modelagem matemática ${ }^{20}$, é consideravelmente mais precoce, ocorrendo 63 dias mais cedo do que o pico de infecções na comunidade. $\mathrm{O}$ mesmo estudo ${ }^{20}$ demonstrou que adiar a prisão de $90 \%$ dos indivíduos de grupos de risco para a COVID-19 reduziria em 56,1\% a mortalidade da doença nos presídios. Embora apenas $1,5 \%$ da população prisional seja idosa no Brasili ${ }^{22}$, o próprio encarceramento degrada a saúde das pessoas, deixando-as mais vulneráveis à infecção e a resultados graves da infecção.

É consenso de que uma ação efetiva para mitigar a evolução da pandemia nos ambientes correcionais é a libertação, temporária ou definitiva, de presos. A exemplo, o Irã libertou 70.000 indivíduos até então reclusos ${ }^{7}$. Dois artigos ${ }^{10,13}$ que discutem a situação atual de imigrantes presos nos Estados Unidos defendem libertar todos os indivíduos que não representam uma ameaça à segurança local, além de cessar momentaneamente a política de encarceramento contra a imigração ilegal adotada nos últimos anos. Yang e Thompson ${ }^{11}$ sugerem que sentenças para pessoas julgadas com delitos leves sejam alternativas à privação de liberdade.

A $\mathrm{OMS}^{18}$ recomenda que sejam priorizados que indivíduos que compõem o grupo de risco para COVID-19 deixem as prisões, se não oferecerem perigo à sociedade. Um argumento importante para esta medida é trazido pelo pressuposto $^{20}$ de que a interrupção da prisão de indivíduos por crimes leves, com a redução geral de detenções em aproximadamente $83 \%$, resultaria em $71,8 \%$ menos infecções na população encarcerada. Essa estratégia ${ }^{20}$ também levaria a 2,4\% menos infecções entre os funcionários e a 12,1\% na comunidade em geral.

Políticas públicas de mitigação da desigualdade devem acompanhar as decisões judiciais de libertação dessas pessoas, uma vez que muitos egressos do sistema prisional não possuem suporte familiar e social. Isso pode levar ao efeito contrário desejado com a libertação desses indivíduos e estes se tornarem portadores e transmissores do SARS-CoV-2 enquanto buscam por renda, moradia, ou mesmo, passem a compor a população em situação de rua ${ }^{16}$. Stephenson ${ }^{15}$ lembra que na Califórnia e em Nova Iorque, o poder público está alugando quartos de hotel para alguns desses presos postos em liberdade. Assim, libertar indivíduos presos deve ser uma ação intersetorial, em que participem poder público, assistência social, ONGs, serviços de saúde e o judiciário.

Se, contudo, a única medida for reduzir o tamanho da população carcerária, haverá uma negligência quanto a inúmeras outras coisas que devem ser feitas ${ }^{17}$. As estratégias de mitigação nos centros de detenção devem ser complementadas por procedimentos rotineiros de triagem e contenção. Isso envolve a triagem de todas as pessoas que entram nas instalações, incluindo novos presos, funcionários, visitantes e fornecedores, colocando em quarentena aqueles que são positivos para a exposição ao novo coronavírus ${ }^{10}$.

Outras medidas são sugeridas na bibliografia revisada. Yang e Thompson ${ }^{11}$ sugerem intensificar a educação em saúde para presos e funcio- 
nários do sistema penitenciário. Todos devem receber treinamento sobre como identificar sinais de COVID-19 e meios de prevenir a doença. Suspensão de visitas de familiares e advogados e redução de transferências são propostas por Akiyama, Spaulding e Rich ${ }^{7}$ sugerindo, ainda, que teleconferência seja aplicada nesses casos, a fim de reduzir o isolamento emocional. A limpeza e desinfecção dos ambientes, bem como compra de produtos de higiene pessoal e de máscaras devem ser efetuadas pelo poder público ${ }^{12,14}$.

Nas publicações revisadas, também foi posto que as medidas devem levar em conta que as reações psicológicas de pessoas privadas de liberdade podem diferir das observadas em pessoas que observam o distanciamento social na comunidade, uma vez que, na prisão, haverá um superisolamento. As consequências não intencionais dessas políticas de mitigação devem ser consideradas.

As recentes rebeliões nos presídios italianos revelaram o potencial de impacto psicológico negativo das políticas de emergência destinadas a reduzir a disseminação do SARS-CoV-2 em instituições penais ${ }^{14}$. Deve-se considerar, portanto, a crescente necessidade de apoio emocional e psicológico, a conscientização e o compartilhamento transparentes de informações sobre a doença e a garantia de que o contato contínuo com a família será mantido ${ }^{18}$, para que as pessoas privadas de liberdade possam colaborar nas estratégias de mitigação à pandemia.

\section{COVID-19 em presídios no mundo}

A presente revisão visa evidenciar que, a despeito do que se tem feito por pessoas privadas de liberdade na atual pandemia, ainda é insuficiente e marginalizante. Em 2018, havia mais de 10 milhões de pessoas privadas de liberdade em todo o mundo ${ }^{23}$, grande parte em condições sanitárias precárias, com pouco acesso a serviços de saúde e em instituições com superlotação. A população penitenciária de vários países, bem como egressos do sistema penal, sofre com estigma ${ }^{4}$, abandono do poder público e o que o filósofo Mbembe chama de necropolítica ${ }^{24}$, fundamentada num Estado de Exceção, em que este tem o poder de ditar quem deve viver e quem deve morrer, desprovendo do sujeito seu status político e, se não ativamente tirando-lhe a vida, expondo-lhe à morte.

Para obter informações sobre como diferentes países estão lidando com a pandemia no contexto penitenciário, foram revisadas e sumarizadas informações contidas na iniciativa Prison Insider ${ }^{25}$, criada pelo fundador do Observatório
Internacional de Prisões. O site reúne informações atualizadas sobre diversos aspectos das prisões no mundo e, atualmente, dispõe de uma área voltada ao novo coronavírus. Ressalta-se, no entanto, que há uma limitação dessas informações, uma vez que nem todos os países ou organizações disponibilizam os dados e, quando o fazem, não é em tempo real.

Até 05 de maio de 2020, havia 145 países com dados apresentados e, no total, 23.019 registros de infecções pelo SARS-CoV-2, sendo os Estados Unidos o primeiro, com mais de $17 \mathrm{mil}$ pessoas privadas de liberdade infectadas ${ }^{25}$. Por outro lado, há denúncias em diversos países de falta de transparência nos dados ${ }^{26,27}$. A fiscalização por parte de ativistas, organizações internacionais e parlamentares tem sido comprometida ${ }^{27,28}$ sob o pretexto de redução do acesso a prisões devido à COVID-19. Foi expressa ${ }^{29}$ a preocupação de que na Síria o regime possa estar usando a pandemia para se livrar de presos, endurecendo a repressão contra esses e, da mesma forma, prisioneiros palestinos têm sido mais expostos ao novo vírus em prisões israelenses ${ }^{30}$.

$\mathrm{Na}$ Figura 1, constam as medidas praticadas por diversos países, sumarizadas através de nossa revisão da iniciativa Prison Insider ${ }^{24}$.

Algo que poderia ser efetivo foi informado apenas 5 dos 145 países revisados ${ }^{25}$ : testagem em massa dos indivíduos presos. As duas medidas mais praticadas são a suspensão ou redução de visitas e a libertação de presos. Ressalta-se, contudo, que mesmo havendo grande número de presos sendo libertos, as instituições ainda se encontram aquém de comportar tantas pessoas.

Há relatos de que o excesso de presos, aliado ao medo de adoecer e à suspensão de visitas em diversas localidades tem causado rebeliões instituições penais. Para exemplificar: em Luxemburgo, houve relato de greve de fome ${ }^{31}$. $\mathrm{Na}$ Itália, rebeliões foram relatadas em diversas áreas do país ${ }^{32}$. Na Argentina, houve pelo menos uma morte e diversos feridos em decorrência de revoltas ${ }^{33}$.

A efervescência ocorrida nas prisões pode estar associada com a pouca informação de qualidade em saúde passada às pessoas reclusas. Poucos foram os países que informaram ter investido na educação em saúde, frente ao contexto da pandemia. A OMS $^{18}$ ressalta a importância de oferecer informações adequadas e garantias legais às pessoas privadas de liberdade, a fim de tranquilizar a elas e suas famílias.

Se por um lado, presos devem ser resguardados por políticas de saúde pública eficientes, 


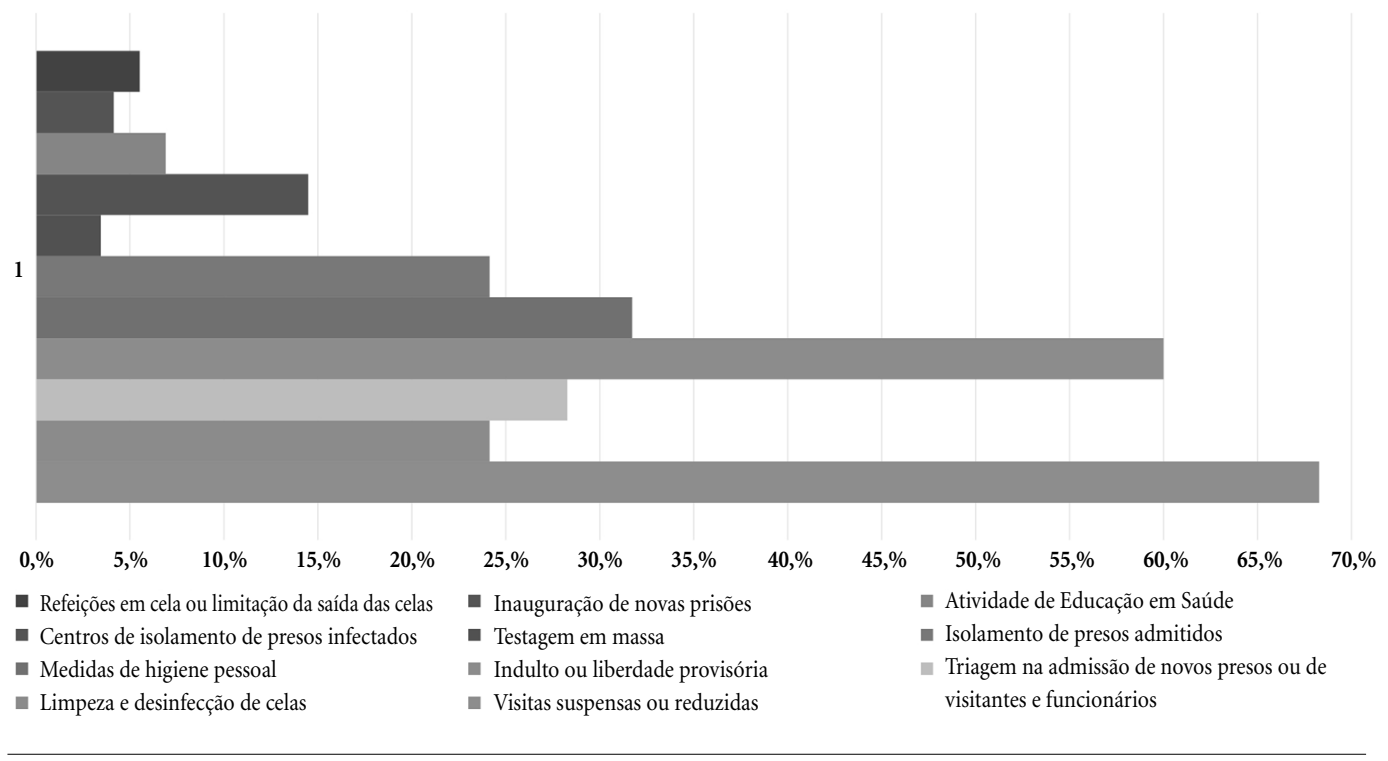

Figura 1. Medidas de combate ao novo coronavírus em prisões no mundo.

por outro, participam ativamente do combate ao SARS-CoV-2. Diversos países têm reportado que a população penitenciária está trabalhando voluntariamente na confecção de máscaras para serem distribuídas em serviços de saúde e na comunidade. Na Guatemala, um jovem preso relatou à reportagem enquanto fazia máscaras: "Se eu fui capaz de prejudicar a Guatemala no passado, hoje quero compensar meus erros"34.

\section{O enfrentamento ao coronavírus no sistema penitenciário brasileiro}

No Brasil, as necessidades de saúde das pessoas privadas de liberdade estão sob a responsabilidade do Estado, como previsto pela Lei de Execução Penal (LEP) ${ }^{35}$, mas também têm sido implantadas políticas para a inclusão da população prisional no âmbito do SUS. Em 2014, foi instituída a Política Nacional de Atenção Integral à Saúde da Pessoa Privada de Liberdade (PNAISP) ${ }^{36}$, cujo objetivo está centrado na garantia do atendimento às pessoas privadas de liberdade em todos os níveis de complexidade, ampliando e organizando desde as formas de financiamento das equipes de saúde prisional até as principais ações de saúde para as pessoas presas.

Um desafio para sistemas penitenciários do mundo inteiro, a COVID-19, cujo tratamento mais efetivo está na prevenção da sua transmissão, higiene individual e de espaços coletivos, ambientes ventilados e isolamento social ${ }^{1}$, expõe a precariedade das prisões no Brasil. Tal desafia gestores no sentido de garantir a efetivação das ações previstas na PNAISP, bem como para os profissionais de saúde que estão na linha de frente em unidades prisionais a se organizarem frente aos riscos de uma explosão de casos e óbitos.

Em 2019, havia 1.422 unidades prisionais no Brasil, das quais $49 \%$ é destinada à detenção de presos provisórios e 79\% se encontra com superlotação ${ }^{22}$. Metade das instituições prisionais não possuem consultório médico. Segundo o Departamento Penitenciário Nacional ${ }^{22}$, no mesmo ano, havia 755.274 pessoas privadas de liberdade no país, das quais $31 \%$ são presas provisórias.

O Brasil acatou as medidas propostas pela $\mathrm{OMS}^{18}$ em relação à população privada de liberdade através da Recomendação 62/2020 do Conselho Nacional de Justiça (CNJ) ${ }^{37}$. Esta envolve medidas desencarceradoras e de não aprisionamento, além de outras ações sanitárias, detalhadas no Quadro 3. A Recomendação $62 / 2020^{37}$ considera como pertencente ao grupo de risco: idosos; gestantes; pessoas com doenças crônicas, respiratórias ou com condições imunossupressoras.

Além das recomendações supracitadas, a Sociedade Brasileira de Medicina de Família e Co- 
Quadro 3. Medidas de combate ao novo coronavírus no Sistema Penal brasileiro.

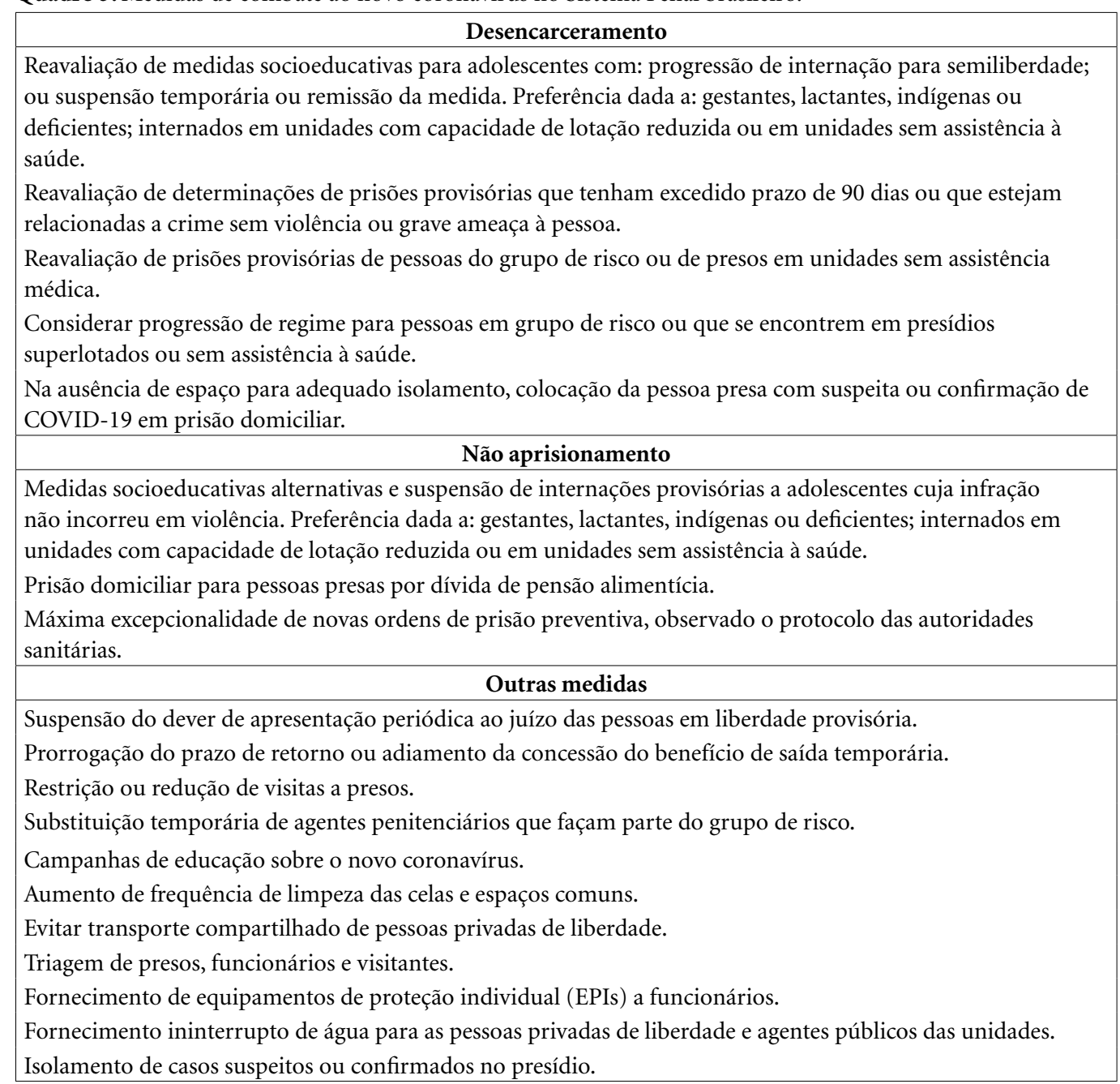

munidade emitiu um documento salientando a necessidade de outras medidas: ações educativas, combate às fake news, higiene individual e coletiva, higiene dos ambientes, fornecimento de informações aos familiares e higiene do material de higiene dos profissionais de segurança, envolvendo ações para os prisioneiros e os diversos profissionais penitenciários ${ }^{38}$.

Até o dia 11 de maio de 2020, havia 603 casos de COVID-19 confirmados em prisões brasileiras, resultando em 23 óbitos $^{22}$. Com apenas 20 dias, os números saltaram de 1 para mais de 100, no Brasil ${ }^{39}$. Apesar das recomendações e esforços da sociedade civil, há muito a ser feito. Uma entidade religiosa com trabalho em presídios divulgou o dado de que $65,9 \%$ de alimentos e materiais de higiene enviados por familiares não estavam entrando as prisões ${ }^{40}$. A mesma organização religiosa cita a falta de transparência e de EPIs, além de precárias condições de higiene, como o relato de que 35 presos estariam usando a mesma escova de dentes ${ }^{41}$.

Chama a atenção que, dos 603 casos de COVID-19 em presídios brasileiros, 444 (74\%) estejam no Complexo Penitenciário da Papuda ${ }^{42}$, no Distrito Federal, instituição que abriga muitos políticos presos e criminosos de maior poder aquisitivo. $\mathrm{O}$ dado pode evidenciar uma desigualdade no Sistema Penitenciário que reproduz a da sociedade em geral, em que há mais acesso a testes para o novo coronavírus quando se ocupa posição de privilégio social ou financeiro. 


\section{Considerações finais}

O PNAISP e as recomendações do CNJ, adaptados à realidade de cada local são iniciativas significativas no cuidado à saúde de pessoas privadas de liberdade e dão visibilidade a essa problemática sensível e relevante para a saúde pública, tendo em vista que, por serem instituições porosas, os agravos que incidem nas prisões não ficam restritos a ela.

O enfrentamento da COVID-19 nas instituições prisionais brasileiras, como em boa parte do mundo, se constitui um desafio, tendo em vista a precariedade que lhes caracterizam, fruto de descaso crônico do poder público e da sociedade civil, que conferem aos presos um agravamento ilegítimo da sentença formal, como exemplo, a negação de condições sanitárias básicas, como o acesso à água potável.

Nesse sentido, em tempos de pandemia, o cenário prisional se agrava com a superposição de problemas, pré-existentes e novos, que exigem medidas sanitárias mais agressivas, tais como a suspensão de visitas e outras, que resultam no superisolamento, que, além de tudo, pode afetar a saúde mental das pessoas privadas de liberdade.
As medidas de contenção à pandemia tomadas no mundo revelam que há um consenso em liberar presos e suspender visitas, mas outras ações são postas de lado, tais como educação em saúde e testes em massa na população carcerária, que poderia ajudar nas projeções epidemiológicas, tendo em vista que são grupos fechados e controlados. Outro consenso é que a falta de dados em saúde disponibilizados sobre essa população impede a adoção de medidas mais efetivas.

As publicações científicas relacionadas à COVID-19, bem como de outras doenças infecciosas, na população carcerária são escassas, apontando para um possível desinteresse por esse tema pela comunidade científica, podendo ser resultante do estigma e da dificuldade de acesso a esse grupo.

Diante do exposto, a pandemia pelo novo coronavírus vem tendo um papel revelador das condições insalubres e desumanas destinadas à recuperação de seres humanos. Que o poder público, a sociedade civil e a comunidade científica possam tirar algo de positivo da atual crise de saúde pública, a fim de mudar o destino de populações vulneráveis!

\section{Colaboradores}

SG Carvalho, ABS Santos e IM Santos participaram na concepção, revisão de literatura e de dados, redação, revisão crítica e aprovação final do manuscrito.

\section{Agradecimentos}

Agradecimentos ao professor Hélio Marques da Silva, pela tradução do artigo, e a Richard Luiz Eduardo e Antônio Teixeira, por suas contribuições. 


\section{Referências}

1. Jin Y, Yang H, Ji W, Wu W, Chen S, Zhang W, Duan G. Virology, Epidemiology, Pathogenesis, and Control of COVID-19. Viruses 2020; 12(4):E372.

2. Mizumoto K, Chowell G. Transmission potential of the novel coronavirus (COVID-19) onboard the diamond Princess Cruises Ship, 2020. Infect Dis Model 2020; 5:264-270.

3. Finnie TJ, Copley VR, Hall IM, Leach S. An analysis of influenza outbreaks in institutions and enclosed societies. Epidemiol Infect 2014; 142(1):107-113.

4. Goffman E. Estigma: notas sobre a manipulação da identidade deteriorada. Rio de Janeiro: Zahar; 1982.

5. World Prison Brief (WPB). Highest to Lowest - Occupancy level (based on official capacity) [Internet]. 2020 [cited 2020 Apr 30]. Available from: https://www.prisonstudies.org/highest-to-lowest/occupancy-level?field_region_taxonomy_tid=All

6. NPR. Coronavirus Found In China Prisons, As Cases Spike In South Korea [Internet]. 2020 [cited 2020 Apr 30]. Available from: https://www.npr. org/2020/02/21/808002924/coronavirus-found-inchina-prisons-as-cases-spike-in-south-korea

7. Akiyama MJ, Spaulding AC, Rich JD. Flattening the Curve for Incarcerated Populations - Covid-19 in Jails and Prisons. N Engl J Med 2020; 382:2075-2077.

8. Sylverken A, El-Duah P, Owusu M, Yeboah R, Kwarteng A, Ofori L, Gorman R, Obiri-Danso K, Owusu-Dabo E. Burden of respiratory viral infections among inmates of a Ghanaian prison. 2019 [preprint].

9. Simpson PL, Butler TG. Covid-19, prison crowding, and release policies. BMJ 2020; 369:m1551.

10. Meyer JP, Franco-Paredes C, Parmar P, Yasin F, Gartland M. COVID-19 and the coming epidemic in US immigration detention centres. Lancet Infect Dis 2020; 20(6):646-648

11. Yang H, Thompson JR. Fighting covid-19 outbreaks in prisons. BMJ 2020; 369:m1362.

12. Kinner SA, Young JT, Snow K, Southalan L, Lopez-Acuña D, Ferreira-Borges C, O’Moore É. Prisons and custodial settings are part of a comprehensive response to COVID-19. Lancet Public Health 2020; 5(4):e188-e189.

13. Keller AS, Wagner BD. COVID-19 and immigration detention in the USA: time to act. Lancet Public Health 2020; 5(5):e245-e246.

14. Wurcel AG, Dauria E, Zaller N, Nijhawan A, Beckwith C, Nowotny K, Brinkley-Rubinstein L. Spotlight on Jails: COVID-19 Mitigation Policies Needed Now. Clin Infect Dis 2020:ciaa346.

15. Stephenson J. COVID-19 Pandemic Poses Challenge for Jails and Prisons. InJAMA Health Forum 2020; 1(4):e200422-e200422b.

16. Gorman G, Ramaswamy M. Detained during a pandemic: A postcard from the Midwest. Public Health Nurs 2020; 37(3):325-326

17. Rubin R. The challenge of preventing COVID-19 spread in correctional facilities. JAMA 2020; 323(18):1760-1761.

18. World Health Organization (WHO). Preparedness, prevention and control of COVID-19 in prisons and other places of detention. Interim guidance 15 March 2020. Copenhagen: WHO; 2020.
19. Liebrenz M, Bhugra D, Buadze A, Schleifer R. Caring for persons in detention suffering with mental illness during the Covid-19 outbreak. Forensic Science International: Mind and Law 2020; 1:100013.

20. Lofgren E, Lum K, Horowitz A, Madubuowu B, Fefferman N. The Epidemiological Implications of Incarceration Dynamics in Jails for Community, Corrections Officer, and Incarcerated Population Risks from COVID-19. medRxiv 2020 [preprint].

21. Mabud TS, Alves MD, Ko AI, Basu S, Walter KS, Cohen T, Mathema B, Colijn C, Lemos E, Croda J, Andrews JR. Evaluating strategies for control of tuberculosis in prisons and prevention of spillover into communities: An observational and modeling study from Brazil. PLoS Med 2019; 16(1):e1002737.

22. Brasil. Departamento Penitenciário Nacional (DEPEN). INFOPEN [Internet]. 2017 [cited 2020 May 11]. Available from: http://depen.gov.br/DEPEN/depen/ sisdepen/infopen

23. Walmsley R. International World Prison Population List. Birkbeck, University of London: ICPR; 2018.

24. Mbembe A. Necropolitics. Durham: Duke University Press; 2019.

25. Prison Insider. Coronavirus: la fièvre des prisons [Internet]. 2020 [cited 2020 May 5]. Available from: https://www.prison-insider.com/articles/coronavirus-la-fievre-des-prisons

26. The Marshall Project. As COVID-19 Measures Grow Prison Oversight Falls [Internet]. 2020 [cited 2020 May 1]. Available from: https://www.themarshallproject.org/2020/03/17/as-covid-19-measures-grow-prison-oversight-falls

27. Sobesednik. Vladimir Osechkin: I'm afraid that prison statistics on COVID-19 are falsified [Internet]. 2020 [cited 2020 May 1]. Available from: https:// sobesednik.ru/obshchestvo/20200331-vladimir-osechkin-boyus-chto-t?fbclid=IwAR3Bi0kBBpFujMihl1XnyFFXqsuD9rXBg5iH_1ppwE3Ry8bjmLBZULCENYwvid-19-measures-grow-prison-oversight-falls

28. France 3. Coronavirus: le député LFI Ugo Bernalicis conteste son interdiction de visiter la prison de Sequedin [Internet]. 2020 [cited 2020 May 1]. Available from: https://france3-regions.francetvinfo.fr/hauts-defrance/coronavirus-depute-lfi-ugo-bernalicis-conteste-son-interdiction-visiter-prison-sequedin-1817236. html

29. Syria Direct. Coronavirus: The Syrian regime's novel weapon against detainees [Internet]. 2020 [cited 2020 May 4]. Available from: https://syriadirect.org/news/ coronavirus-the-syrian-regime $\% \mathrm{E} 2 \% 80 \% 99$ s-novel-weapon-against-detainees/

30. Middle East Monitor. Israel's jail conditions will kill Palestinian prisoners before coronavirus does [Internet]. 2020 [cited 2020 May 4]. Available from: https://www.middleeastmonitor.com/20200414-israels-jail-conditions-will-kill-palestinian-prisoners-before-coronavirus-does/\#comment-4876974513

31. RTL. 30 inmates embark on hunger strike following protests [Internet]. 2020 [cited 2020 May 2]; Available from: https://today.rtl.lu/news/luxembourg/a/1493481.html 
32. Prison Insider. Italie: révoltes dues au coronavirus, douze prisonniers décédés [Internet]. 2020 [cited 2020 May 2]. Available from: https://www.prison-insider.com/ articles/italie-revoltes-dues-au-coronavirus-douze-prisonniers-decedes?referrer=\%2Fpreview.php\%2Farticles\%2Fcoronavirus-la-fievre-des-prisons

33. Clarín. Un muerto en un motín en dos cárceles de Santa $F e$ : reclaman medidas de seguridad por el coronavirus [Internet]. 2020 [cited 2020 May 7]. Available from: https://www.clarin.com/policiales/graves-disturbios-carceles-santa-fe-reclaman-medidas-seguridad-coronavirus_0_z6ZWKbGfp.html

34. CNN. Coronavirus en Guatemala: Jóvenes fabrican al menos 5.000 mascarillas desde la prisión [Internet]. 2020 [cited 2020 May 6]. Available from: https://cnnespanol.cnn.com/video/coronavirus-mascarillas-jovenes-prision-ciudad-guatemala-pandemia-pkg-digital-orig-michelle-mendoza/

35. Brasil. Lei no 7.210, de 11 de julho de 1984. Institui a Lei de Execução penal. Diário Oficial da União 1984; 13 jul.

36. Brasil. Portaria Interministerial $\mathrm{n}^{\circ} 1$, de 02 de janeiro de 2014. Institui a Política Nacional de Atenção Integral à Saúde das Pessoas Privadas de Liberdade no Sistema Prisional (PNAISP) no âmbito do Sistema Único de Saúde (SUS). Diário Oficial da União; 2014.

37. Conselho Nacional de Justiça (CNJ). Recomendação $n^{\circ}$ 62, de 17 de março de 2020. Recomenda aos Tribunais e magistrados a adoção de medidas preventivas à propagação da infecção pelo novo coronavírus - Covid-19 no âmbito dos sistemas de justiça penal e socioeducativo. Diário Oficial da União; 2020.

38. SBMFC. Medidas e orientações para o enfrentamento da COVID-19 nas prisões [Internet]. 2020 [cited 2020 Apr 29]. Available from: https://www.sbmfc. org.br/wp-content/uploads/2020/03/Medidas-e-orientac\%CC\%A7o\%CC\%83es-para-o-enfrentamento-a-COVID-\%E2\%80\%93-19-nas-priso \%CC\%83es.pdf
39. Ponte. Casos de coronavírus em prisões vão de 1 a 107 em 20 dias, com 7 mortes [Internet]. 2020 [cited 2020 Apr 8]. Available from: https://ponte.org/casos-decovid-19-em-prisoes-vao-de-1-a-107-em-20-diascom-7-mortes/

40. Pastoral Carcerária. Pastoral Carcerária divulga dados de questionário sobre coronavírus nas prisões [Internet]. 2020 [cited 2020 May 6]. Available from: https:// carceraria.org.br/combate-e-prevencao-a-tortura/ pastoral-carceraria-divulga-dados-de-questionario-sobre-coronavirus-nas-prisoes

41. Pastoral Carcerária. Pastoral Carcerária divulga relatos e denúncias sobre o sistema carcerário em tempos de pandemia [Internet]. 2020 [cited 2020 May 6]. Available from: https://carceraria.org.br/combate-e-prevencao-a-tortura/pastoral-carceraria-divulga-relatos-e-denuncias-sobre-o-sistema-carcerario-em-tempos-de-pandemia

42. Correio Braziliense. Número de presos infectados pelo coronavírus na Papuda chega a 444 [Internet]. 2020 [cited 2020 May 14]. Available from: https:// www.correiobraziliense.com.br/app/noticia/cidades/2020/05/11/interna_cidadesdf,853723/numero-de-presos-infectados-pelo-coronavirus-na-papuda-chega-a-444.shtml

Artigo apresentado em 21/05/2020

Aprovado em 24/05/2020

Versão final apresentada em 26/05/2020 